\title{
Selective nitrate detection by an enzymatic sensor based on an extended-gate type organic field-effect transistor
}

Tsuyoshi Minami, ${ }^{\mathrm{a}, *}$ Yui Sasaki, ${ }^{\mathrm{a}}$ Tsukuru Minamiki, ${ }^{\mathrm{a}}$ Shin-ichi Wakida, ${ }^{\mathrm{b}}$ Ryoji Kurita, ${ }^{c}$ Osamu Niwa ${ }^{\text {a,d }}$ and Shizuo Tokito ${ }^{a}$

${ }^{a}$ Research Center for Organic Electronics (ROEL), Graduate School of Science and Engineering, Yamagata University, 4-3-16 Jonan, Yonezawa, Yamagata 992-8510 Japan.

${ }^{\mathrm{b}}$ Health Research Institute, National Institute of Advanced Industrial Science and Technology (AIST), 2217-14 Hayashi, Takamatsu, Kagawa 761-0395, Japan.

${ }^{c}$ Biomedical Research Institute, National Institute of Advanced Industrial Science and Technology (AIST), Tsukuba Central 6, 1-1-1 Higashi, Tsukuba, Ibaraki 305-8566, Japan.

d Advanced Science Research Laboratory, Saitama Institute of Technology, Fukaya, Saitama 369-0293, Japan.

Tel: +81-238-26-3594; Fax: +81-238-26-3788

E-mail: tminami@yz.yamagata-u.ac.jp

\begin{abstract}
First selective nitrate biosensor device based on an extended-gate type organic field-effect transistor (OFET) is reported. The fabricated sensor device consists of the extended-gate electrode functionalized by a nitrate reductase with a mediator (=a bipyridinium derivative) and an OFET-based transducer. The mechanism of the nitrate detection can be explained by an electron-relay on the extended-gate electrode, resulting in changes of the electric properties of the OFET. The detection limit of nitrate in water
\end{abstract}


is estimated to be $45 \mathrm{ppb}$, which suggests that the sensitivity of our fabricated sensor is comparable to those of some conventional detection methods. As a practical application of the OFET sensor, the nitrate detection in diluted human saliva has been successfully demonstrated; the results agreed well with those by conventional colorimetric measurement. The advantages of OFETs are printability, mechanical flexibility, stretchability and disporsability, meaning that the fabricated OFET could open up a new approach for low-cost electronic devices toward on-site detection of nitrate in aqueous media.

Keywords: Organic field-effect transistor, organic electronics, enzymatic sensor, nitrate, nitrate reductase

\section{Introduction}

Since the discovery of the field-effect phenomenon of organic semiconductors in 1984 (Kudo et al., 1984), a great deal of attention has been paid to organic field-effect transistors (OFETs) worldwide (Sirringhaus, 2014). Because OFETs possess intriguing properties such as printability, stretchability, mechanical flexibility and low fabrication costs, their practical applications have been exploring even though the improvement of the field-effect mobility of OFETs is still an ongoing project. To date, rollable activematrix displays (Gelinck et al., 2010), radio-frequency identification (RFID) tags (Subramanian et al., 2005) and flexible nonvolatile memories (Heremans et al., 2011) have been successfully demonstrated. In that regard, biosensors based on OFETs are one of the more promising applications, having a great potential toward the development of wearable and disposable healthcare devices. Toward that end, OFET 
sensors have been applied to the detection of biologically active substances such as immunoglobulins (Hammock et al., 2014; Minamiki et al., 2015 and Palazzo et al., 2015), saccharides (Liu et al., 2008 and Minami et al., 2014), small anionic species (Khodagholy et al., 2012 and Minami et al., 2015a, 2015b), biogenic amines (Diallo et al., 2009 and Minami et al., 2015c), neurotransmitters (Casalini et al., 2013 and Jang et al., 2015), etc. The development of OFET-based biosensors has just begun to bloom in recent years (Lin and Yan, 2012; Torsi et al., 2013 and Manoli et al., 2015).

In this context, we decided to develop a selective nitrate sensor device using OFET. Nitrate ion $\left(\mathrm{NO}_{3}{ }^{-}\right)$is not only often employed as a food additive but also ubiquitously contained in environmental water and drinking one, over-ingestion of which could cause serious diseases such as bladder or gastric cancer, infant methemoglobinemia, etc (Bruning-Fann and Kaneene, 1993 and Ellis et al., 1998). In addition, the nitrate level in saliva might be related with psychological stress (Jin et al., 2013 and Kitamura et al., 2012). The detection methodology for nitrate has been thus researched, and a couple of powerful detection methods based on colorimetric (Monteiro et al., 2003) or fluorometric (Biswas et al., 2004) spectroscopy, ion chromatography (Shu-yu, et al., 2013) or ion-sensitive inorganic field-effect transistors (Zayats et al., 2001 and Wakida et al., 2007) were successfully demonstrated. Although ion-sensitive inorganic FETs are well known as a reliable method, OFET capable of sensing nitrate could pave the way to a new approach for disposable electronic devices toward on-site detection of nitrate. Herein we report for the first nitrate sensor device based on the OFET. The fabricated OFET possesses an extended-gate which is functionalized with a nitrate reductase and an electron-transfer mediator $(=\mathrm{a}$ 
bipyridinium derivative (BP)) (Fig. 1). The electron-transfer mediator is immobilized on the extended-gate electrode, the upside of which is covered by the nitrate reductase. Sodium dithionite exists in aqueous solutions, which serves as an electron donor to the enzyme (Zayats et al., 2001). An electron-relay on the extended-gate electrode thus occurs, being able to cause the reduction of nitrate. We demonstrate here that the nitrate detection could be achieved by changes in electrical characteristics of the OFET based on such electron-relay.

\section{Experimental}

\subsection{Fabrication of the OFET}

The OFET sensor device consists of the drive unit (the OFET) and the detection electrode (the extended-gate) (Fig. 1). The low-voltage operation $(<3 \mathrm{~V})$ was attained by employing $\mathrm{AlOx}$ with tetradecylphosphonic acid $\left(\mathrm{C}_{14}-\mathrm{PA}\right)$ as the gate dielectric layer (Klauk et al., 2007 and Fukuda et al., 2009). An easy fabrication was enabled using solution-processable PBTTT (poly\{2,5-bis(3-hexadecylthiophene-2-yl)thieno[3,2b]thiophene $\}$ ) as the active layer (McCulloch et al., 2006 and Umeda et al., 2009). To obtain a stable operation, the active layer was passivated with a fluoropolymer $\left(\right.$ Cytop $\left.^{\circledR}\right)$. More details of reagents, instruments and the fabrication process of the OFET are summarized in the supplementary material.

\subsection{Functionalization of the Extended-Gate Electrode}

The extended-gate electrode, which was the detection portion made of gold (50 $\mathrm{nm})$, was prepared on a polyethylene naphthalate film (125 $\mu \mathrm{m}$ thick) using thermal evaporation, such that the sensing area was $15 \mathrm{~mm}^{2}$. The prepared extended-gate 
electrode was washed with water and methanol, followed by immersion in a methanol solution of 2-aminoethanethiol $(10 \mathrm{mM})$ for $1 \mathrm{~h}$ at room temperature. After this period, the electrode was immersed in a HEPES (=2-[4-(2-hydroxyethyl)piperazin-1yl]ethanesulfonic acid) buffer solution (10 mM, pH 7.4) containing $N$-methyl- $N$ '(carboxyethyl)-4,4'-bipyridinium (Willner et al., 1994) (20 mM), HOBt (=1hydroxybenzotriazole $) \quad(20 \quad \mathrm{mM}) \quad$ and $\quad$ EDC $\quad(=1-$ Ethyl-3-(3dimethylaminopropyl)carbodiimide) hydrochloride $(20 \mathrm{mM})$ for $2 \mathrm{~h}$ at room temperature. By a drop-casting method, the fabricated electrode was coated with the nitrate reductase from Aspergillus niger (60 units / mL) in a HEPES buffer solution (10 $\mathrm{mM}, \mathrm{pH}$ 7.4). The coated electrode was allowed to stand for $1 \mathrm{~h}$ at room temperature. The electrode was subsequently covered with glutaraldehyde (10 vol\%). To immobilize the nitrate reductase on the electrode by glutaraldehyde, it was allowed to stand for 30 min at room temperature. Finally, the extended-gate electrode was washed with a HEPES buffer solution (10 mM, pH 7.4).

\section{Results and Discussion}

\subsection{Characterization of the Fabricated OFET Sensor}

The fabricated OFET device could be operated reproducibly at below $-3 \mathrm{~V}\left(=V_{\mathrm{GS}}\right.$ $\left.=V_{\mathrm{DS}}\right)$ under ambient conditions, the field-effect mobility and on/off drain current ratio of which were estimated to be $0.02 \mathrm{~cm}^{2} / \mathrm{Vs}$ and $\sim 10^{3}$, respectively. Repeated measurements for the evaluation of the electric stability showed that the transfer curve did not shift against DC bias stress (See the supplementary material, Fig. S1). Although the electric performance (such as switching response) of the developed OFET is not high in comparison with that of the conventional ion-sensitive inorganic FETs, one of the advantage is that the fabrication process of the OFET is much simpler and easier 
(See Section 2.1). Together, these results indicated that the OFET is enough to be applied in chemical sensing (Minamiki et al., 2014).

Next, we confirmed the formation of 2-aminoethanethiol self-assembled monolayer and the attachment of the BP on the gold electrode using photoelectron yield spectroscopy (PYS) in air. The results of PYS exhibited a lower work function on the 2aminoethanethiol-treated gold electrode $(4.2 \mathrm{eV})$ than that on an untreated gold electrode (4.6 eV) (Fig. S2), which suggested that the electron-donating group capped the gold electrode (de Boer et al., 2005). Additionally, a measurement of wettability showed the contact angle of the 2-aminoethanethiol modified electrode $\left(48^{\circ} \pm 4.4^{\circ}\right)$, which is higher than that of the untreated gold electrode $\left(40^{\circ} \pm 1.9^{\circ}\right)$ (Fig. S3). This stems from hydrophobicity of the 2-aminoethanethiol. Moreover, we measured PYS and wettability after the immersion of the electrode into the aqueous solution with BP. A dramatic downshift of the work function $(5.3 \mathrm{eV})$ and a higher contact angle were observed, which is presumed to be due to the positively charged bipyridinium unit on the gold electrode. To obtain further evidence for the attachment of BP on the gold electrode, we also measured X-ray photoelectron spectroscopy (XPS) that suggested the presence of nitrogen, sulfur, and oxygen (Fig. S4). Overall, these characterization data are in support of the assertion that the functionalization of the gold electrode with BP was successfully attained. Thus, we covered the gold electrode using the nitrate reductase, and the fixation of the enzyme was performed by the cross-linking agent (=glutaraldehyde).

\subsection{Response Time of the Fabricated OFET to the Nitrate Addition}

The successful characterization of the fabricated OFET allowed us to evaluate the sensing ability of the OFET for the nitrate detection in aqueous media. In conventional 
OFET-based biosensors, the surface of the organic semiconducting layer employs as both of a detection portion and a drive unit (Stoliara et al., 2009). Although such structure can offer a very compact device, degradation of OFET by water often occurs and thereby offers an unreproducible sensing response. In our design, the drive unit passivated by the fluoropolymer is completely separated from the detection portion (=the extended-gate electrode), which can provide the stable operation and the reproducible response. The extended-gate electrode and the OFET were connected and the electrode was dipped into a HEPES buffer solution with sodium dithionite at $\mathrm{pH} 7.4$ at room temperature. The gate voltage was applied through a silver/silver chloride and the initial bias-stress on the device was eliminated by the operation of the OFET $\left(V_{\mathrm{DS}}=V_{\mathrm{GS}}=\right.$ $-2.0 \mathrm{~V}$ ) for $1 \mathrm{~h}$. The output characteristics of the OFET upon addition of nitrate was then measured using a source meter. Fig. 2a displays the time course change of the output current $\left(I_{\mathrm{DS}}\right)$ for the nitrate addition. As expected, we observed a clear response to the addition of nitrate. The $90 \%$ response time of the OFET for the nitrate addition was within $20 \mathrm{sec}$, which is comparable with that of the inorganic FET-based nitrate sensor (Zayats et al., 2001) and much faster than that of the other optical spectroscopic methods (Monteiro et al., 2003 and Biswas et al., 2004).

\subsection{Changes in the OFET Transfer Characteristics with Addition of Nitrate and Its}

\section{Selectivity}

We also measured the transfer characteristics of the OFET upon titration with the HEPES solution of nitrate. As a consequence, the titration experiment indicated a negative shift of the transfer curve with increasing the nitrate concentration (Fig. 2b). The valence of the electron mediator $(=\mathrm{BP})$ on the extended-gate electrode is changed when the enzyme reaction occurs (i.e. $\mathrm{BP}^{2+} \leftrightarrow \mathrm{BP}^{+}$), which results in the change of the 
potential difference between the reference and the extended-gate electrodes. Because channel conductance within the OFET (which is closely related with the $V_{\mathrm{TH}}$, see the supplementary material) is affected by the potential difference (Bergveld, 2003), the $V_{\mathrm{TH}}$ shift upon addition of nitrate was observed. To confirm the electrical response arose from the electron-relay (Zayats et al., 2001), we carried out the similar titration experiment in the absence of sodium dithionite. As predicted, almost no electrical changes of the OFET were observed by addition of nitrate (Fig. S5). These data strongly supported that the enzymatic reaction based on the electron-relay induced the changes in OFET characteristics.

To evaluate the selectivity of the OFET sensor, we also titrated some representative small anions such as chloride $\left(\mathrm{Cl}^{-}\right)$, thiocyanate $\left(\mathrm{SCN}^{-}\right)$, hydrogen phosphate $\left(\mathrm{HPO}_{4}{ }^{2-}\right)$ and bicarbonate $\left(\mathrm{HCO}_{3}{ }^{-}\right)$. Fig. 3(c) displays the relationship between the anion concentration and changes in the threshold voltage $\left(V_{\mathrm{TH}}\right)$. As expected, we observed a highly selective response to nitrate. This also supported that the electrical changes in the OFET is arising from the enzymatic reaction. A linear relationship was obtained in the region of the low concentration $\left(0-4.0 \times 10^{-6} \mathrm{M}\right)$, allowing to estimate the limit of detection (LOD) (Miller and Miller, 2010) as $45 \mathrm{ppb}$. The LOD obtained is lower than or comparable to those of the inorganic FET-based sensor (Zayats et al., 2001), electrochemical (Monea et al., 2010), colorimetric (Monteiro et al., 2003) and fluorometric (Biswas et al., 2004) methods, while that of high-performance liquid chromatography (5 ppb, Shu-yu et al., 2013) is further lower than our OFET-based sensing system. However, the further improvement of sensitivity could be achieved by OFET-based amplifiers (Fukuda et al., 2015), which is thus in progress in our laboratory.

\subsection{Nitrate Detection in Diluted Human Saliva}


The nitrate level in saliva might be associated with psychological stress (Jin et al., 2013). For instance, a ship navigator's mental workload was evaluated by monitoring of salivary nitrate, resulting in that the level seemed to increase in response to psychological stress during navigation (Kitamura et al. 2013). Toward the evaluation of feasibility of the OFET sensor for practical applications, we executed the nitrate detection in diluted human saliva (Fig. 3). The saliva samples from a healthy volunteer were used as obtained including proteins such as amylase (Zakowski et al., 1985 and Nater et al., 2005), lactoferrin (Glimvall et al., 2012), myeloperoxidase (Thomas et al., 1994), etc. The detection of nitrate in human saliva is authorized by the Ethics Committee of Yamagata University (authorization code: 27-10). As a result, the threshold voltage of the fabricated OFET device was changed with increasing of the nitrate level (Fig. 3). The recovery for the standard nitrate solution added to the samples was estimated to be $97.4 \pm 1.8 \%(\mathrm{n}=3)$ (addition amount: $24 \mu \mathrm{M})$, suggesting that the analytical accuracy of the OFET sensor is comparable to that of a commercially available and colorimetric method based on a diazo coupling of sulfanilamide and $\mathrm{N}$-(1naphthyl) ethylenediamine by nitrite generated using zinc reduction of nitrate $(100.4 \pm 5.2 \%,(n=3))$. Thus, the fabricated OFET could be employed for the specific detection of nitrate contained in biological fluids such as saliva.

\section{Conclusion}

We have successfully developed the highly selective and sensitive nitrate biosensor based on the extended-gate type OFET. Importantly, the nitrate detection has been demonstrated in diluted human saliva containing various proteins. The LOD obtained was $45 \mathrm{ppb}$. This paper will dictate the criteria for the highly sensitive detection of nitrate using OFET biosensors. We believe our preliminary results have 
implications that will impact the future development of disposable electronic devices for biosensing applications.

\section{Acknowledgments}

We gratefully acknowledge the financial support from Japan Science Technology Agency (JST, the Center of Innovation Program), and Japan Society for the Promotion of Science (JSPS, Grant-in-Aid for Research Activity Start-up, No.26888002). We also thank Prof. P. Anzenbacher, Jr. and P. Koutnik of Bowling Green State University, Dr. K. Fukuda of RIKEN, Dr. D. Kumaki and T. Sekine of Yamagata University for their technical support and valuable feedback.

\section{Appendix A. Supplementary material}

Supplementary data associated with this article can be found in the online version at $*$.

\section{References}

Bergveld, P., 2003. Sens. Actuators B 88, 1-20.

Biswas, S., Chowdhuzy, B., Ray, B.C., 2004. Talanta 64, 308-312.

Bruning-Fann, C.S., Kaneene, J.B. 1993. Vet. Hum. Toxicol. 35, 237-253.

Casalini, S., Leonardi, F., Cramer, T., Biscarini, F., 2013. Org. Electron. 14, 156-163.

Diallo, A. K., Tardy, J., Zhang, Z. Q., Bessueille, F., Jaffrezic-Renault, N., Lemiti, M., 2009. Appl. Phys. Lett. 94, 263302-1-3.

de Boer, B., Hadipour, A., Mandoc, M. M., van Woudenbergh, T., Blom, P.W.M., 2005. Adv. Mater. 17, 621-625.

Ellis, G., Adatia, I., Yazdanpanah, M., Makela, S.K., 1998. Clin. Biochem. 31, 195-220. Fukuda, K., Hamamoto, T., Yokota, T., Sekitani, T., Zschieschang, U., Klauk, H., Someya, T., 2009. Appl. Phys. Lett. 95, 203301-3. 
Fukuda, K., Minamiki, T., Minami, T., Watanabe, M., Fukuda, T., Kumaki, D., Tokito, S., 2015. Adv. Electron. Mater. 1, 1400052.

Gelinck, G., Heremans, P., Nomoto, K., Anthopoulos, T.D., 2010. Adv. Mater. 22, $3778-3798$.

Glimvall, P., Wickström, C., Jansson, H., 2012. J. Periodont. Res. 47, 655-660.

Hammock, M.L., Knopfmacher, O., Ng, T.N., Tok, J. B.-H., Bao, Z., 2014. Adv. Mater. $26,6138-6144$.

Heremans, P., Gelinck, G.H., Müller, R., Baeg, K.-J., Kim. D.-Y., Noh, Y.-Y., 2011. Chem. Mater. 23, 341-358.

Jang, M., Kim, H., Lee, S., Kim, H.W., Khedkar, J.K., Rhee, Y.M., Hwang, I., Kim, K., Oh, J.H., 2015. Adv. Funct. Mater. 25, 4882-4888.

Jin, L., Qin, L., Xia, D., Liu, X., Fan, Z., Zhang, C., Gu, L., He, J., Ambudkar, I.S., Deng, D., Wang, S., 2013. Free Radic. Biol. Med. 57, 61-67.

Khodagholy, D., Curto, V.F., Fraser, K.J., Gurfinkel, M., Byrne, R., Diamond, D., Malliaras, G.G., Benito-Lopez, F. Owens, R.M., 2012. J. Mater. Chem. 22, 44404443.

Kim, D., Goldberg, I. B., Judy, J. W., 2009. Sens. Actuators B 135, 618-624.

Kitamura, K., Murai, K., Fukushi, K., Hayashi, Y., Mitomo, N., Yoshimura, K., Hikida, K., Wakida, S., Miyado, T., 2012. Proceedings of the IEEE International Conference on Systems, Man, and Cybernetics, SMC 2012, Seoul, Korea, 15311535.

Kitamura, K., Murai, K., Wakida, S., Miyado, T., Fukushi, K., Hayashi, Y., 2013. IEEJ Trans. 8, 301-302.

Klauk, H., Zschieschang, U., Pflaum, J., Halik, M., 2007. Nature 445, 745-748. 
Kudo, K., Yamashina, M. Moriizumi, T. 1984. Jpn. J. Appl. Phys. 23, 130.

Lin, P., Yan, F., 2012. Adv. Mater. 24, 34-51.

Liu, J., Agarwal, M., Varahramya, K., 2008. Sens. Actuators B 135, 195-199.

Manoli, K., Magliulo, M., Mulla, M.Y., Singh, M., Sabbatini, L., Palazzo, G., Torsi, L., 2015. Angew. Chem. Int. Ed. 54, 12562-12576.

McCulloch, I., Heeney, M., Bailey, C., Genevicius, K., MacDonald, I., Shkunov, M., Sparrowe, D., Tierney, S., Wagner, R., Zhang, W., Chabinyc, M.L., Kline, R.J., Mcgehee, M.D., Toney, M.F., 2006. Nat. Mater. 5, 328-333.

Miller, J.N., Miller, J.C., 2010. Statistics and chemometrics for analytical chemistry, 6th ed. Pearson, Harlow, UK.

Minami, T., Minamiki, T., Hashima, Y., Yokoyama, D., Sekine, T., Fukuda, K., Kumaki, D., Tokito, S., 2014. Chem. Commun. 50, 15613-15615.

Minami, T., Sato, T., Minamiki, T., Fukuda, K., Kumaki, D., Tokito, S., 2015a. Biosens. Bioelectron. 74, 45-48.

Minami, T., Minamiki, T., Tokito, S., 2015b. Chem. Commun. 51, 9491-9494.

Minami, T., Sato, T., Minamiki, T., Tokito, S., 2015c. Anal. Sci. 31, 721-724.

Minamiki, T., Minami, T., Kurita, R., Niwa, O., Wakida, S., Fukuda, K., Kumaki, D., Tokito, S., 2014. Appl. Phys. Lett. 104, 243703-1-4.

Minamiki, T., Minami, T., Sasaki, Y., Kurita, R., Osamu, N., Wakida, S., Tokito, S., 2015. Anal. Sci. 31, 725-728.

Monea, F., Remes, A., Radovan, C., Pode, R., Picken, S., Schoonman, J., 2010. Talanta $83,66-71$.

Monteiro, M.I.C., Ferreira, F.N., de Oliveira, N.M.M., Ávila, A.K., 2003. Anal. Chim. Acta 477, 125-129. 
Nater, U.M., Rohleder, N., Gaab, J., Berger, S., Jud, A., Kirschbaum, C., Ehlert, U., 2005. Int. J. Psychophysiol. 55, 333-342.

Palazzo, G., De Tullio, D., Magliulo, M., Mallardi, A., Intranuovo, F., Mulla, M.Y., Favia, P., Vikholm-Lundin, I., Torsi, L., 2015. Adv. Mater. 27, 911-916.

Shu-yu, Z., Qing, S., Li, L., Xiao-hui, F., 2013. Biomed. Chromatogr. 27, 1547-1553.

Sirringhaus, H., 2014. Adv. Mater. 26, 1319-1335.

Subramanian, V., Fréchet, J.M.J., Chang, P.C., Huang, D.C., Lee, J.B., Molesa, S.E., Murphy, A.R., Redinger, D.R., Volkman, S.K., 2005. Proceedings of the IEEE 93, $1330-1338$.

Stoliara, P., Bystrenova, E., Quiroga, S.D., Annibale, P., Facchini, M., Spijkman, M., Setayesh, S., de Leeuw, D., Biscarini, F., 2009. Biosens. Bioelectron. 24, 29352938.

Thomas, E.L., Jefferson, M.M., Joyner, R.E., Cook, G.S., King, C.C., 1994. J. Dent. Res. 73, 544-555.

Torsi, L., Magliulo, M., Manoli, K., Palazzo, G., 2013. Chem. Soc. Rev. 42, 86128628.

Umeda, T., Kumaki, D., Tokito, S., 2009. J. Appl. Phys. 105, 024516-1-5.

Wakida, S., Okumura, T., Shibutani, Y., Liu, J., 2007. Sens. Mater. 19, 235-247.

Willner, I., Lapidot, N., Riklin, A., Kasher, R., Zahavy, E., Katz, E. 1994. J. Am. Chem. Soc. $116,1428-1441$.

Zakowski, J.J., Bruns, D.E. 1985. Crit. Rev. Clin. Lab. Sci. 21, 283-322.

Zayats, M., Kharitonov, A.B., Katz, E. Willner, I. 2001. Analyst 126, 652-657. 


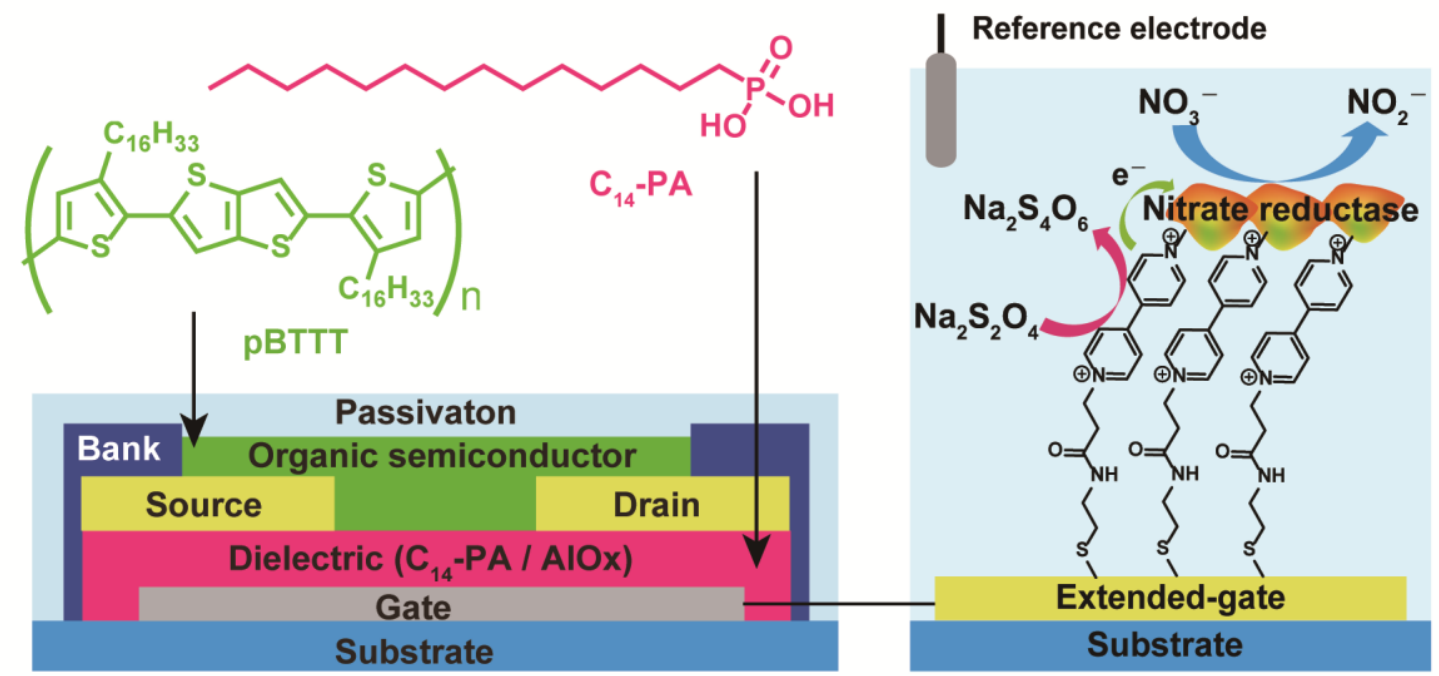

Fig. 1. Schematic illustration of the nitrate sensing device based on the extended-gate type OFET biosensor. 

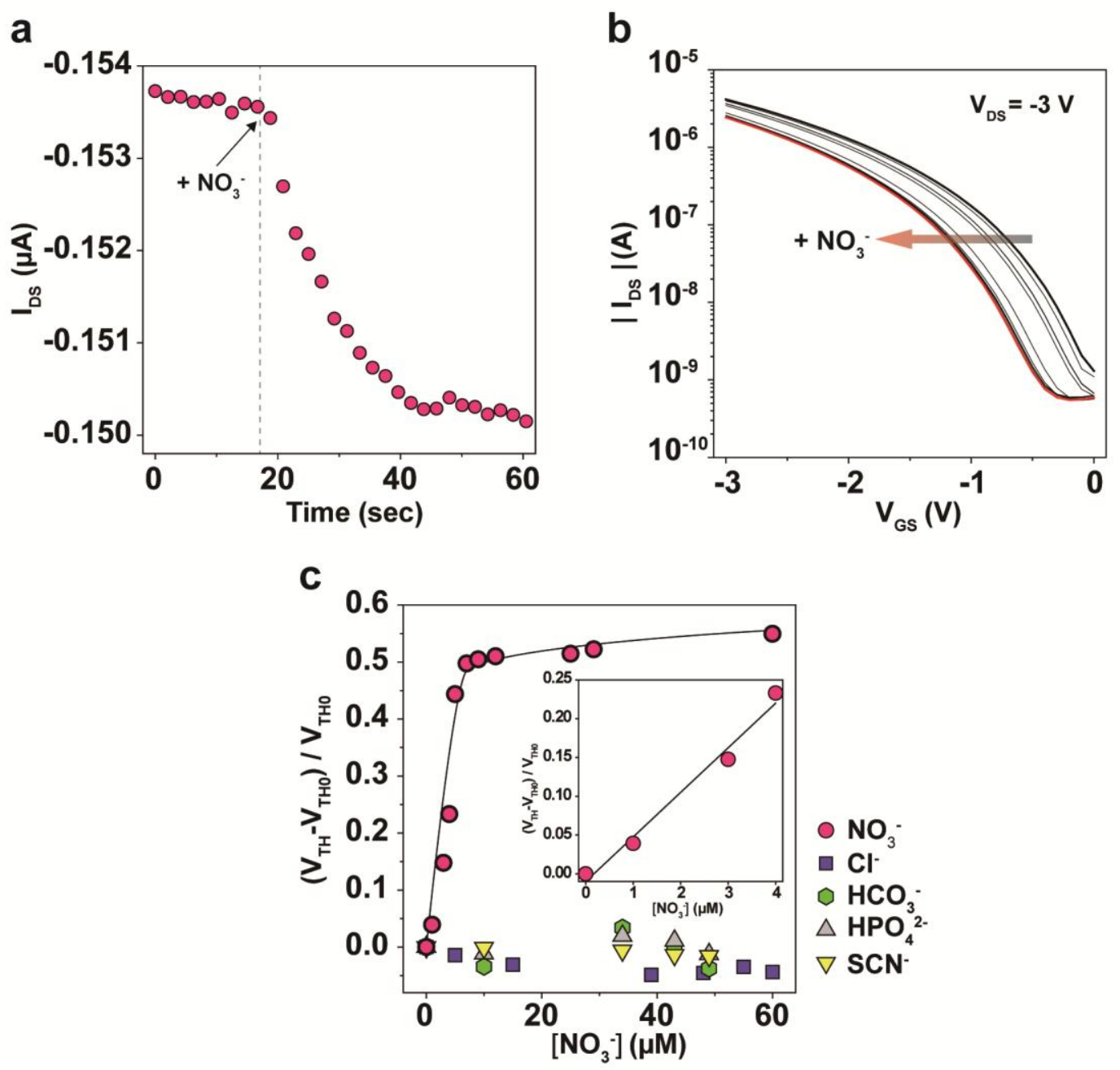

Fig. 2. (a) Time course change of the drain current $\left(I_{\mathrm{DS}}\right)$ by addition of nitrate. $V_{\mathrm{DS}}=$ $V_{\mathrm{GS}}=-2.0 \mathrm{~V}$. [Nitrate $]=600 \mu \mathrm{M}$. (b) Transfer characteristics $\left(I_{\mathrm{DS}}-V_{\mathrm{GS}}\right)$ of the OFET sensor upon titration with nitrate in a HEPES-buffer solution $(10 \mathrm{mM})$ with $\mathrm{Na}_{2} \mathrm{~S}_{2} \mathrm{O}_{4}(20 \mathrm{mM})$ at $\mathrm{pH} 7.4$ at room temperature. $V_{\mathrm{DS}}=-3.0 \mathrm{~V}$. [Nitrate] $=0-60$ $\mu \mathrm{M}$. (c) Changes in the threshold voltage $\left(V_{\mathrm{TH}}\right)$ of the OFET device by adding anions at various concentrations in a HEPES-buffer solution $(10 \mathrm{mM})$ with $\mathrm{Na}_{2} \mathrm{~S}_{2} \mathrm{O}_{4}(20 \mathrm{mM})$ at $\mathrm{pH} 7.4$ at room temperature. The lower end of the nitrate titration. 


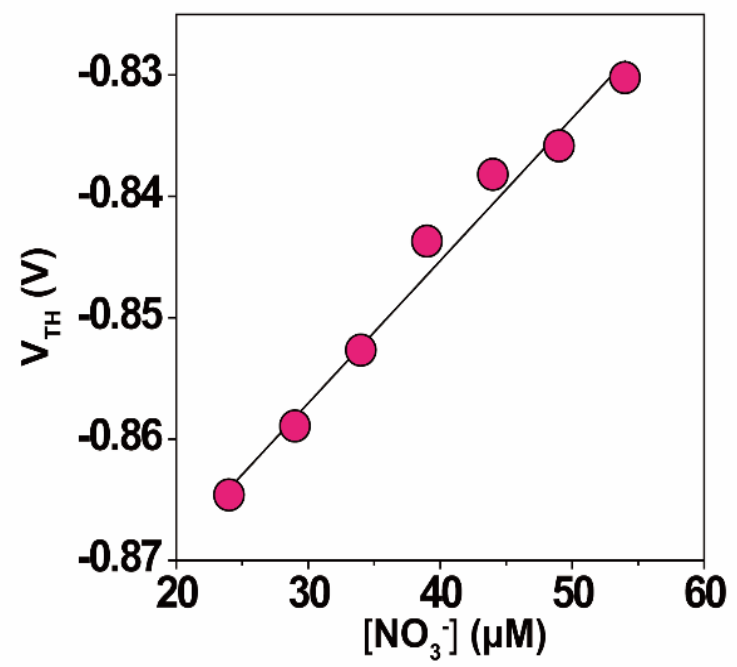

Fig. 3. Changes in the threshold voltage $\left(V_{\mathrm{TH}}\right)$ of the OFET by nitrate at various concentrations in diluted human saliva (human saliva : HEPES $=1: 9$, v/v) with $\mathrm{Na}_{2} \mathrm{~S}_{2} \mathrm{O}_{4}(20 \mathrm{mM})$ at room temperature. [Nitrate] $=24-54 \mu \mathrm{M} . \mathrm{R}^{2}>0.98$. 
TOC

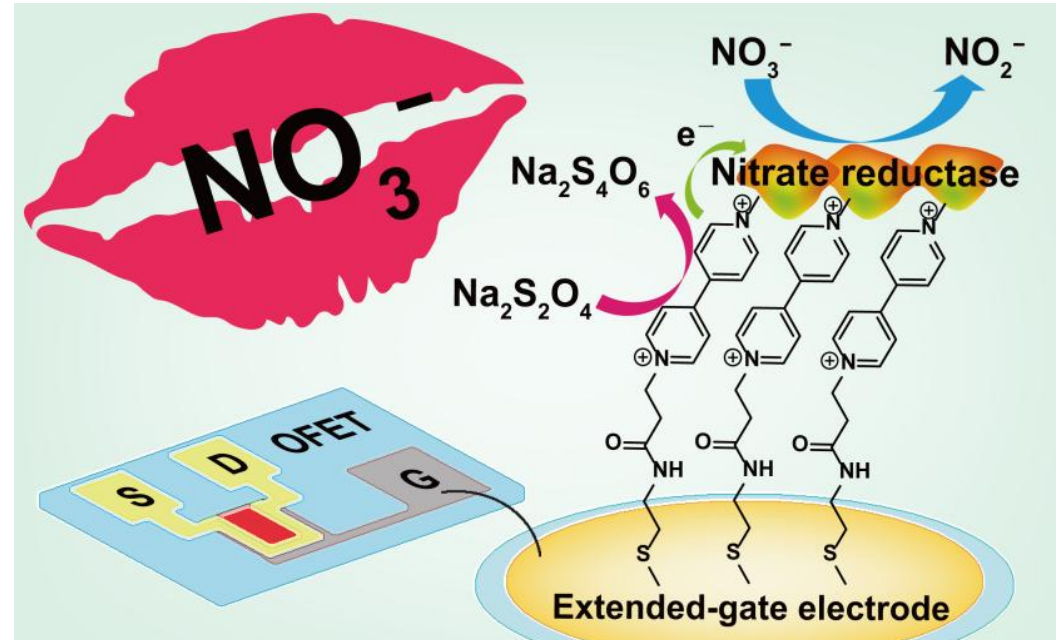

